\title{
COVID-19 E IMIGRAÇÃO INTERNACIONAL NA REGIÃO METROPOLITANA DE SÃO PAULO
}

\author{
Covid-19 and International Immigration in the Metropolitan \\ Region of São Paulo
}

\author{
Luís Felipe Aires Magalhães* \\ Lúcia Bógus** \\ Rosana Baeninger ${ }^{* * *}$
}

\begin{abstract}
Resumo. A pandemia da Covid-19 tem evidenciado o efeito das múltiplas formas de desigualdades sobre as condições de vida da população. Seu padrão de disseminação demonstra que a metropolização, produto e produtora da mobilidade humana, constitui fator central da expansão do número de casos e de óbitos. O Brasil, país estruturalmente desigual, apresenta dificuldades importantes para entendermos a forma específica com que a Covid-19 afeta os imigrantes, pois a nacionalidade não é um quesito dos registros médicohospitalares. Este artigo tem como objetivo analisar os impactos da Covid-19 entre imigrantes internacionais na Região Metropolitana de São Paulo, utilizando dados da pesquisa "Impactos da Pandemia de Covid nas Migrações Internacionais" (PUC-MG, UNICAMP, 2020). Abordaremos, especialmente, o perfil sócio-demográfico dos respondentes e os impactos da pandemia nas condições de trabalho e acesso a direitos. Parte de estudo mais amplo em andamento, este artigo visa ainda explicitar as relações entre epidemiologia e mobilidade humana.
\end{abstract}

Palavras-chave: Covid-19; imigração internacional; Região Metropolitana de São Paulo; trabalho; direitos sociais.

Abstract. The Covid-19 pandemic has shown the effect of multiple forms of
inequality on the population's living conditions. Its pattern of dissemination
demonstrates that metropolization, a product and producer of human mobility,
is a central factor in the expansion of the number of cases and deaths. Brazil,
as structurally unequal country, presents important difficulties in understanding

* Coordenador-Adjunto do Observatório das Migrações em São Paulo (NEPO-Unicamp). São Paulo, SP, Brasil. E-mail: lufeaires@gmail.com. Orcid: https://orcid.org/0000-0002-5839-786X.

** Professora titular do Departamento de Sociologia da Pontifícia Universidade Católica de São Paulo (PUC-SP). São Paulo, SP, Brasil. E-mail: lubogus@uol.com.br. Orcid: https://orcid.org/0000-00023431-7298.

*** Docente do Programa de Pós-Graduação em Demografia e do Programa de Pós-Graduação em Sociologia do Instituto de Filosofia e Ciências Humanas - UNICAMP. Campinas, SP, Brasil. E-mail: baeninger@nepo.unicamp.br. Orcid: https://orcid.org/0000-0002-3817-2807. 
the specific way in which Covid-19 affects immigrants, as nationality is not a question of medical and hospital records. This article aims to analyze the impacts of Covid-19 among international immigrants in the Metropolitan Region of São Paulo, using data from the survey "Impacts of Covid's Pandemic on International Migration" (PUC-MG, UNICAMP, 2020). We will address, in particular, the respondents' socio-demographic profile and the impacts of the pandemic on working conditions and access to rights. Part of a broader study in progress, this article also aims to explain the relationship between epidemiology and human mobility.

Keywords: Covid-19; international immigration; Metropolitan Region of São Paulo; labor; social rights.

\section{Introdução}

A eclosão, a princípios do ano de 2020, da pandemia da Covid-19 tem se convertido em um fenômeno que rapidamente extrapola seus contornos epidemiológicos e apresenta dimensões políticas, sociais e econômicas complexas, que exigem, para seu entendimento, uma análise precisa dos fatores envolvidos em seu padrão de disseminação e, também, uma reflexão crítica sobre as formas de enfrentamento à pandemia.

Tendo a natureza pandêmica de seu padrão de disseminação declarado pela OMS em 11 de março de 2020, a Covid-19 é registrada pela primeira vez no Brasil em 26 de fevereiro do mesmo ano. Tratou-se de um típico caso de transmissão importada: um brasileiro retornado da Itália, residente na cidade de São Paulo, e que manifestara os sintomas da doença alguns dias antes. O primeiro óbito registrado no Brasil ocorre, também, na cidade de São Paulo, no dia 12 de março. No dia 26 do mesmo mês de março, a Fundação SEADE (Sistema Estadual de Análise de Dados, do Estado de São Paulo) inicia sua série de registros de casos e de óbitos ${ }^{1}$ - neste dia, já havia 994 casos e 57 óbitos pela doença nos 39 municípios que compõem a RMSP.

A disseminação da Covid-19 nos municípios brasileiros perfaz uma trajetória que acompanha, de um lado, os eixos rodoviários que interligam os polos metropolitanos inseridos nos circuitos internacionais de circulação de pessoas aos municípios pequenos e médios que se integram à rede urbana destes polos; de outro lado, essa disseminação expressa, ainda, os efeitos das desigualdades sócio espaciais sobre as condições de vida da população brasileira, de modo que investigar a disseminação da Covid-19 no Brasil exige levar em consideração os diferenciais de renda, de escolaridade, de ocupação, de acesso aos serviços de saúde e de bem-estar urbano que sintetizam as condições econômicas, sociais e ambientais no país.

Segundo Jacobi,

\footnotetext{
1 É precisamente esta fonte de dados que utilizaremos para apresentar a evolução do número de casos e de óbitos por Covid-19 na Região Metropolitana de São Paulo (RMSP).
} 
no Brasil, os casos começaram nas classes mais abastadas, até que a doença foi se alastrando para os bairros de menor renda, que também são os mais prejudicados em relação ao acesso a serviços de água e saneamento e de condições básicas de habitabilidade. Juntam-se a essa questão problemas preexistentes, como doenças respiratórias, dengue e tantas outras vinculadas à falta de saneamento que tornam essas populações ainda mais vulneráveis à propagação da COVID-19. (Ziegler, 2020)

Reveladora de nossas desigualdades, a Covid-19 evidencia, com isso, a centralidade do tema da moradia e das condições da habitação na capacidade de resistir à doença. Ademais, revela que muitos setores de atividade econômica, tendo sido declarados essenciais, seguiram funcionando, muitas vezes sem a adoção de cuidados sanitários mínimos; o próprio trabalho informal, dimensão crescente do mundo do trabalho no Brasil, também seguiu expondo contingentes importantes da força de trabalho ao contágio. Segundo Roseta (2020), "embora inicialmente o impacto sanitário tenha atingido sobretudo camadas mais afluentes e com maior mobilidade global, é nas camadas economicamente mais frágeis que a crise se vem agravando a níveis imprevistos" (Roseta, 2020), justamente em razão destas desigualdades e inserção laboral precária.

O citado deslocamento dos casos do centro para a periferia das cidades já havia sido descrito por Bógus e Magalhães (2020) em artigo publicado nos primeiros meses da pandemia. Referindo-se à capital paulista ainda no início de Abril de 2020, os autores observam que

não obstante a doença Covid-19 tenha se manifestado primeiro nas áreas centrais
das sedes metropolitanas, cujos moradores possuem melhores condições de vida e
maiores contatos com o exterior, ela atingiu rapidamente as áreas pobres e muito
precárias, tanto nas periferias distantes como nos enclaves centrais de cortiços
e favelas, onde seus efeitos tendem a ser devastadores (...). A doença percorre
um trajeto urbano iniciado nas áreas mais ricas, nos hospitais particulares,
deslocando-se rapidamente para a periferia, especialmente para as zonas Leste
e Norte da cidade de São Paulo; regiões com grande densidade populacional e
transporte público superlotado. Passa a pressionar com isso, o sistema público
de saúde e os leitos do SUS (...). Embora ainda apresente número menor de
registros de morte, a periferia, pelas condições já expostas aqui, possui uma taxa
superior de crescimento dos óbitos, apontando uma dramática tendência de se
converter em lócus de concentração da Covid-19 na cidade de São Paulo. (Bógus,
Magalhães, 2020, p. 83-86)

A tendência descrita acima se confirma e se aprofunda nos meses seguintes, passando a incorporar outras regiões brasileiras. Segundo o professor Paulo Saldiva, da Faculdade de Medicina da USP, as desigualdades sociais e a superposição de carências tendem a se sobrepor ao padrão etário, incidindo sobre todos os grupos etários e ampliando, com isso, o escopo dos vulneráveis.

No Estado de São Paulo, a vinculação entre as periferias se dá por meio do deslocamento das pessoas através das rodovias. Segundo o professor Domingos Alves, também da Faculdade de Medicina da USP, "a maior parte dos casos do interior paulista está distribuída em cidades cortadas por grandes rodovias que 
ligam esses municípios à capital, como Anhanguera, Dutra, Imigrantes, entre outras" (Machado, 2020).

A síntese de nossas condições urbanas, rodoviárias, econômicas e sociais têm condicionado um padrão de disseminação da Covid-19 nas cidades brasileiras caracterizado por 3 etapas.

Na primeira etapa, iniciada entre fevereiro e março de 2020, os casos se concentraram nas grandes capitais, e especialmente naquelas mais intensamente integradas aos corredores globais de circulação de pessoas. A Covid-19 se disseminou da região central para os bairros periféricos destas cidades, através, sobretudo, do sistema de transporte público.

Na segunda etapa, ocorre o primeiro impulso de interiorização da Covid-19, ainda que dentro dos limites das metrópoles envolvidas. A disseminação se dá especialmente pelo deslocamento de pessoas infectadas, sintomáticas ou não, entre os municípios através de rodovias.

A terceira etapa ocorre com o deslocamento, através de estradas vicinais, de pessoas infectadas com o vírus para as cidades pequenas, afastadas dos municípios polos das regiões metropolitanas, conectadas mais aos municípios médios de seus estados.

As principais Regiões Metropolitanas brasileiras, como apontado por Bógus, Pasternak e Magalhães (2020) apresentaram as três etapas de forma concomitante, tendo em vista a extensa malha urbana formado por municípios intensamente desiguais.

Esse padrão de disseminação evidencia, como vimos, a potencialização que a doença adquire ao circular por contextos urbanos tão desiguais. Tem sido uma constante no debate científico sobre a Covid-19 o papel que as desigualdades sociais têm no agravamento da doença. A superposição de carências faz do contexto social uma variável decisiva, e por tal razão os imigrantes internacionais, cujas interações sócio culturais e inserções laborais têm sido caracterizadas no Brasil por precariedade habitacional, informalidade e segregação, têm sido particularmente afetados pela doença, sendo ainda mais suscetível ao contágio pela Covid-19.

Em que pese a visibilidade crescente que têm assumido, especialmente pela ocupação de espaços públicos (Magalhães, Bógus, Baeninger, 2018), a alteração na Lei de Migrações no final de 2017 (Ramos, Vedovato, Baeninger, 2020) e seu associativismo cultural (Baptista, Magalhães, 2020), os imigrantes seguem invisíveis nas estimativas e dados oficiais sobre óbitos por coronavírus no Brasil, tendo em vista a nacionalidade não ser um quesito dos registros do Ministério da Saúde sobre a doença (Silva, Mortari, Magalhães, Baeninger, 2020). Essa invisibilidade compromete de forma direta não apenas o entendimento mais preciso do impacto da Covid-19 entre os imigrantes como também a formulação 
de políticas públicas específicas de saúde da população imigrante, sobretudo, em tempos de pandemia (Silva et al., 2020).

A inexistência do quesito nacionalidade nos registros e, com isso, a invisibilidade de imigrantes internacionais nas estatísticas de contágio e de óbitos por Covid-19 no Brasil revelam a manutenção de uma fronteira em nosso país: não uma fronteira física, geográfica, dessas que separam as cidades, os estados e os países, mas sim uma fronteira civilizatória, que produz alteridades, que separa níveis de cidadania e de acesso a direitos, dentro da mesma cidade, estado e país (Martins, 1997). Deste modo, a Covid-19 tem explicitado fronteiras civilizatórias históricas e estruturais ${ }^{2}$ de nosso país, que se refletem no acesso desigual aos serviços de saúde (Silva et al., 2020). Negros e negras, imigrantes e refugiados, diaristas, moradores de periferia, trabalhadores informais, populações indígenas entre outros grupos estão situados para além de uma fronteira imposta pela pelo próprio processo de formação de nosso Estado Nacional (Sayad, 1998). Trata-se de uma fronteira sociológica, invisível, mas muito objetiva, que rompe o tecido social urbano, produz invisibilidades e alteridades e reduz ao limite do compreensível a empatia com o outro. Não por outra razão, ao momento em que fechávamos esse artigo, e o Brasil se aproximava da marca de 200 mil mortos por Covid-19, de Norte a Sul se flexibiliza a quarentena, em uma tentativa desumana de um regresso ao "normal" sem a devida reflexão sobre a gravidade do momento. A vigência desta fronteira civilizatória perpetua a indiferença, a falta de empatia e todo e qualquer caminho de construção de uma sociedade mais justa, menos desigual e mais apta a enfrentar com isso os desafios epidemiológicos do presente e do futuro. E isso impacta de forma direta as condições de vida dos imigrantes internacionais no Brasil.

Esse artigo tem por objetivo analisar os impactos da pandemia do novo coronavírus sobre os imigrantes internacionais, buscando, com isso, oferecer subsídios teóricos capazes de dar visibilidade a esta relação que, como dito, os registros oficiais não têm nos permitido identificar. Para tal, apresentaremos dados da pesquisa "Impactos da Pandemia de Covid nas Migrações Internacionais" (PUC-MG, UNICAMP, 2020) relativos aos imigrantes internacionais residentes na Região Metropolitana de São Paulo (RMSP), um grupo formado por 743 imigrantes respondentes de 31 nacionalidades diferentes, que participaram da citada pesquisa entre Maio e Julho de 2020.

2 Essas fronteiras, no entanto, não são intransponíveis, tendo em vista as mobilizações e resistências importantes empenhadas por migrantes e redes de apoio. A respeito destas mobilizações no contexto de ausência do quesito da nacionalidade nos registros, sugerimos a leitura de SILVA, Carla Craice; MAGALHÃES, Luís Felipe Aires. Imigrantes, direitos e a pandemia da Covid-19. In: SANTOS, Márcio André dos; PARADIS, Clarisse. As Humanidades e os Efeitos da COVID-19: Reflexões a partir da UNILAB. Horizontes ao Sul - Dossiê Especial, n. 1, 2020. 


\section{Os Impactos da Pandemia de Covid-19 nos imigrantes internacionais na Região Metropolitana de São Paulo}

Assim como no início da disseminação da Covid-19 no Brasil, também atualmente a RMSP apresenta uma significativa concentração de casos e óbitos pela doença. Em 11 de dezembro de 2020, a RMSP apresentou 45,93\% dos casos e $57,41 \%$ dos óbitos do Estado de São Paulo e 8,9\% dos casos e 13,93\% dos óbitos do Brasil. Dentre os fatores explicativos desta concentração, é possível considerar, de um lado, a pendularidade espacial da população na região, com 1,9 milhão de deslocamentos diários, 671.116 deles com destino a São Paulo, para trabalho e/ou estudo33; e, de outro, o próprio alto nível de integração dos municípios que compõem a RMSP à cidade de São Paulo. Ambos fatores são expressão da vinculação econômica da região às cadeias globais de produção e de valor e aos circuitos internacionais de circulação de pessoas.

Um aspecto importante desta circulação é, precisamente, a imigração internacional. A Pesquisa "Impactos da Pandemia de Covid-19 nas Migrações Internacionais no Brasil" tem buscado identificar, através de uma ampla parceria acadêmica e institucional, as principais repercussões da pandemia de Covid-19 sobre imigrantes internacionais no país, com destaque para as suas mobilidades, condições de saúde, de trabalho e acesso a direitos sociais. A metodologia da pesquisa combina estratégias quali e quantitativas, e neste artigo apresentaremos os principais resultados da estratégia quantitativa, que envolveu diretamente as redes migratórias (Truzzi, 2008), com participação decisiva dos imigrantes para que o questionário on line fosse respondido pelo maior número possível de imigrantes. No Brasil, foram obtidas 2475 respostas, das quais 743 nos municípios da Região Metropolitana de São Paulo ${ }^{4}$.

Na RMSP, a pesquisa envolveu respondentes de 31 nacionalidades, com predominância de imigrantes do Haiti $(50,87 \%$ do total de imigrantes que responderam a pesquisa na RMSP); e da Venezuela (28,53\% do total). Além destas nacionalidades, é importante destacar ainda a participação expressiva

\footnotetext{
3 Importante considerar que esses deslocamentos, cada vez mais, envolvem inclusive outras regiões metropolitanas e aglomerações urbanas, formadoras de uma nova espacialidade urbana, regional e econômica, a Macrometrópole Paulista (MMP). Para aprofundamentos neste tema, ver BÓGUS, Lucia; PASTERNAK, Suzana; MAGALHÃES, Luís Felipe Aires. Metropolização, governança e direito à cidade: dinâmicas, escalas e estratégias. São Paulo: EDUC, PIPEq, 2020; e o recém-lançado BAENINGER, Rosana; DEMÉTRIO, Natália; DOMENICONI, Joice (coords.). Atlas Temático da Macrometrópole Paulista, Regiões Metropolitanas e Regiões Administrativas. Campinas - SP: Núcleo de Estudos 'Elza Berquó' NEPO - Unicamp, 2020.

4 Uma observação importante para o entendimento das especificidades do grupo respondente à pesquisa na RMSP é a de que a pesquisa foi, também, respondida por 203 imigrantes do Interior do Estado de São Paulo. Em alguns momentos, neste artigo, iremos contextualizar as respostas à luz deste grupo. Para acesso ao relatório integral da pesquisa, com dados importantes sobre outros estados brasileiros, acesse <https:/www.nepo.unicamp.br/publicacoes/livros/impactos_ pandemia/COVID\%20NAS\%20MIGRA\%C3\%87\%C3\%95ES\%20INTERNACIONAIS.pdf>.
} 
congoleses, angolanos e colombianos. Ainda que em menor número, imigrantes peruanos, bolivianos e paraguaios também responderam à pesquisa, de modo que as nacionalidades participantes revelam a própria predominância dos fluxos migratórios Sul Sul na migração internacional contemporânea no Brasil (Baeninger et al., 2018), com emergentes e complexas redes migratórias formadas pelos "periféricos na periferia" (Basso, 2015; Villen, 2015).

\section{O perfil dos respondentes à pesquisa na RMSP}

Como definido anteriormente, o padrão de disseminação da Covid-19 e particularmente a interiorização da doença no estado de São Paulo têm sido condicionados de forma direta pela malha rodoviária. Esta malha, integrada à qual estão os municípios com maior intensidade de articulação às cadeias globais de valor e de circulação de pessoas, guarda relação, por consequência, com a própria presença de imigrantes internacionais - o que se manifesta de forma clara no grupo dos respondentes à pesquisa.

Mapa 1 - Imigrantes internacionais participantes da pesquisa por município de residência. Região Metropolitana de São Paulo ( $n=743)$ e Interior do Estado de São Paulo ( $n=203), 2020$

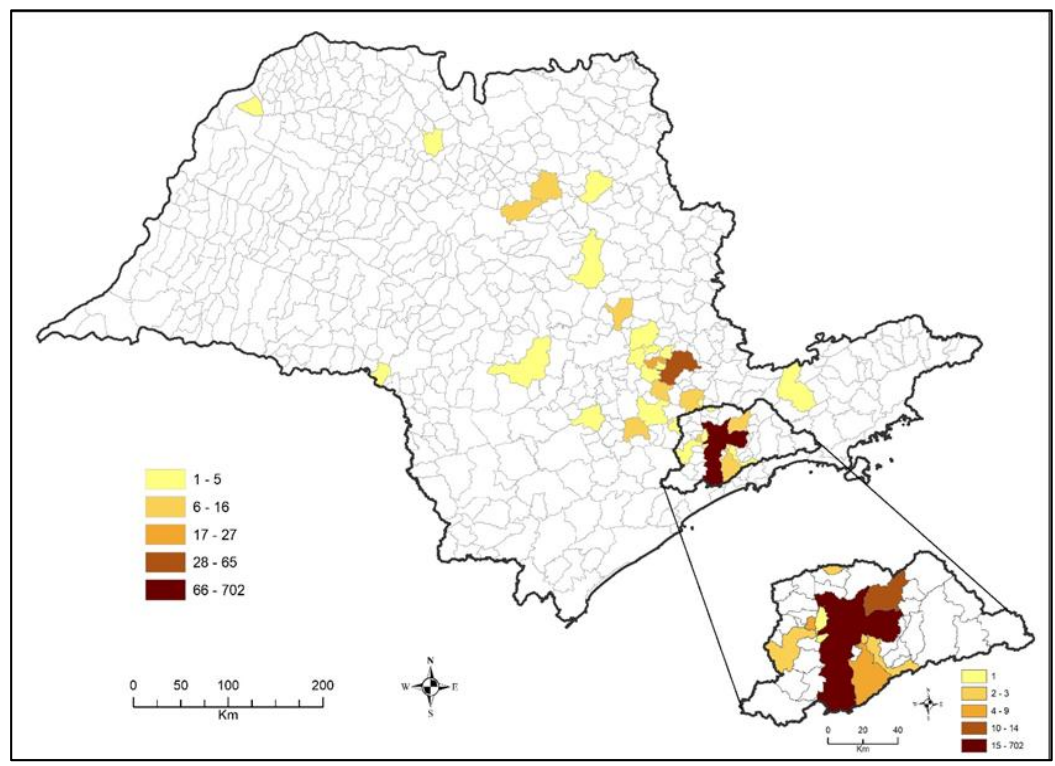

Fonte: Pesquisa Impactos da Pandemia de Covid-19 nas Migrações Internacionais no Brasil. Grupo Interdisciplinar de Pesquisa e Extensão em Direitos Sociais e Migração (GIPE) e do Grupo Distribuição Espacial da População (GEDEP)-PUCMINAS/Observatório das Migrações em São Paulo-NEPO/ UNICAMP, maio a julho de 2020.

Na RMSP, os principais municípios de residência dos imigrantes respondentes à pesquisa foram Carapicuíba, Cotia, Francisco Morato, Guarulhos, Osasco, Santo 
André, São Bernardo do Campo, São Caetano do Sul e São Paulo. Há, claramente, um sentido bem nítido de interiorização por municípios ao redor das Rodovias dos Bandeirantes e Anhanguera, e um sentido, ainda que menos nítido, de interiorização rumo à Região Metropolitana do Vale do Paraíba e Litoral Norte, através da Rodovia Ayrton Senna.

No que tange à estrutura etária e de sexo dos respondentes à pesquisa na RMSP, os resultados apontam para uma concentração nos grupos etários em idades adultas jovens. São imigrantes, homens e mulheres, em idade produtiva e reprodutiva, especialmente de 30 a 34 anos, que sofrem, por isso, de forma direta os impactos econômicos da pandemia. Do grupo de 743 respondentes na RMSP, 335 são mulheres (45,08\% do total de respondentes) e 402 são homens $(54,10 \%$ do total). Embora seja, como visto, um grupo mais masculinizado, isso não diminui a importância da imigração feminina (Baeninger, Peres, 2016).

Do total de 743 respondentes à pesquisa na RMSP, 473 declararam-se negros $(63,66 \%$ do total) 123 declararam-se pardos (16,55\% do total), 121 declararam-se brancos (6,28\% do total), 9 declararam-se indígenas ( $1,21 \%$ do total) e 8 declararam-se asiáticos (1,07\% do total). A composição racial do grupo de respondentes à pesquisa na RMSP é fortemente condicionada pela predominância de imigrantes haitianos (50,87\% do total).

Gráfico 1 - Imigrantes internacionais participantes da pesquisa segundo ano de chegada. Região Metropolitana de São Paulo e Interior do Estado de São Paulo, 2020

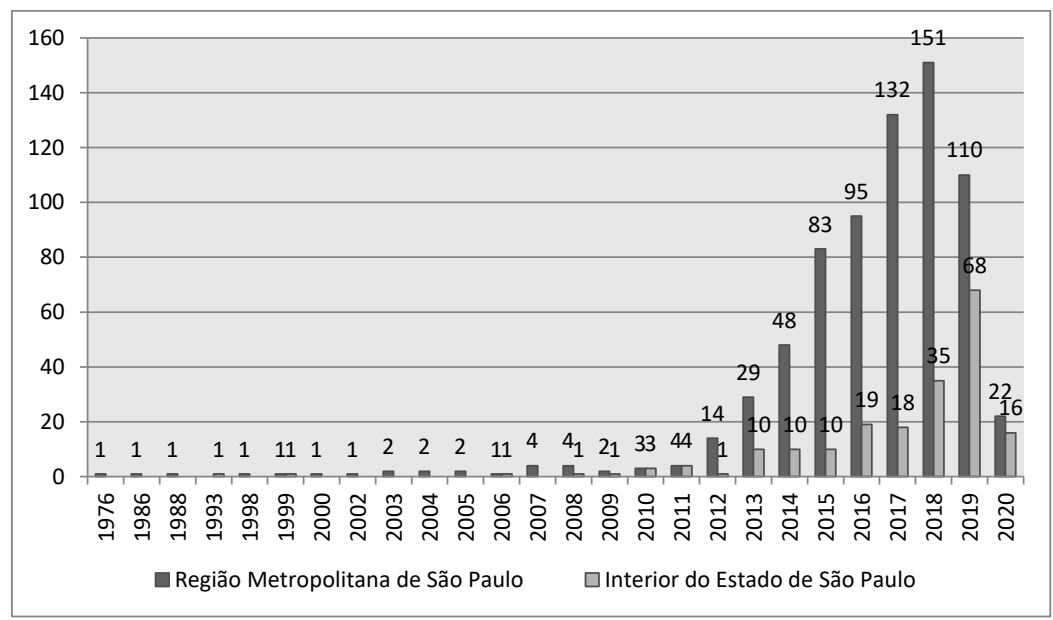

Fonte: Pesquisa Impactos da Pandemia de Covid-19 nas Migrações Internacionais no Brasil. Grupo Interdisciplinar de Pesquisa e Extensão em Direitos Sociais e Migração (GIPE) e do Grupo Distribuição Espacial da População (GEDEP)-PUCMINAS/Observatório das Migrações em São Paulo-NEPO/UNICAMP, maio a julho de 2020 . 
Em relação ao tempo em que estão no Brasil, o Gráfico 1 indica que a maior parte dos respondentes à pesquisa (96\%) declarou ter chegado ao Brasil após 2012. Pouco mais da metade (54,96\%) dos imigrantes que responderam a pesquisa na RMSP chegou ao Brasil somente nos anos de 2017, 2018 e 2019, o que indica um perfil migratório ainda recente. Foram identificadas apenas 22 chegadas no ano de 2020, o que não deixa de ser significativo tendo em vista a declaração da pandemia pela OMS ter se dado no dia 11 de março e o fechamento das fronteiras, pelo Governo Brasileiro, ter ocorrido nos dias 19 (fronteiras terrestres) e 20 (fronteiras aéreas) de março.

A última variável desta descrição do perfil sócio demográfico dos imigrantes participante da pesquisa na RMSP é o status migratório, característica importante das condições - não apenas jurídicas e legais, como também políticas e sociais - dos fluxos, indicando fatores relacionados à permanência, inserção laboral e possibilidade, ou não, de retorno a seu país de origem.

Dos respondentes na RMSP, 209 (28,12\%) afirmaram estar no Brasil com visto humanitário obtido em seu país ou ao entrar no Brasil. Tal condição migratória caracteriza especialmente a imigração haitiana no Brasil (Baeninger et al., 2016). Outro grupo, de 190 respondentes (25,57\%), afirmou estar no Brasil com o status de refugiado - neste grupo estão, por exemplo, venezuelanos, congoleses, colombianos e sírios, presentes dentre os respondentes da RMSP. Outros 182, equivalente a $24,49 \%$, responderam já ter uma autorização de residência temporária ou permanente no Brasil, e um grupo importante, especialmente do ponto de vista de suas restrições ao acesso a direitos, é composto por 139 respondentes $(18,70 \%)$ que afirmaram serem ainda solicitantes de refúgio ou seja, fizeram solicitação de refúgio ao entrar no Brasil e ainda aguardam resposta do Ministério da Justiça. Para esses, a principal, quando não a única, documentação que possuem é o Protocolo de Solicitação de Refúgio, documento que, tendo em vista práticas discriminatórias recorrentes no Brasil, muitas vezes não é aceito para o acesso a direitos no país.

\section{Trabalho e Direitos Sociais}

A situação de vulnerabilidade à que estão, estrutural e historicamente, submetidos os imigrantes internacionais no Brasil, especialmente aqueles de fluxos de países do Sul Global, os periféricos na periferia (Basso, 2015; Villen, 2015) manifesta que, no que se refere ao acesso ao trabalho, a situação já era dramática antes mesmo da pandemia. Na RMSP, a maior parte dos respondentes à pesquisa (429 respondentes, $57,73 \%$ do total) declarou não estar trabalhando antes da pandemia; enquanto 285 (38,35\% do total) declarou estar. Dentre os que estavam trabalhando, destaca-se as ocupações de "trabalhadores dos serviços e vendedores do comércio em lojas e mercados" (108 respondentes, $37,89 \%$ do total), "profissionais das ciências e das artes" (27 respondentes, 9,47\% 
do total) e, ainda, "trabalhadores da produção de bens e serviços industriais" (23 respondentes, $8,07 \%$ do total).

Entre aqueles que responderam estar ocupados antes da pandemia, 108 respondentes $(37,89 \%$ do total) afirmaram que atuavam como "trabalhadores dos serviços e vendedores do comércio em lojas e mercados", 27 respondentes (9,47\% do total) como "profissionais das ciências e das artes" e 23 respondentes (8,07\% do total) como "trabalhadores da produção de bens e serviços industriais".

A Tabela 1 apresenta outra importante informação levantada pela pesquisa: o número de imigrantes que estavam trabalhando antes e após o início da pandemia. Trata-se de um indicador direto do efeito da pandemia na ocupação, pois nos permite identificar, através da diferença entre a primeira (antes da pandemia) e a segunda (depois do início da pandemia) situação, aqueles que perderam ou que conseguiram emprego.

Tabela 1 - Imigrantes internacionais participantes da pesquisa segundo inserção laboral antes e depois do início da pandemia de Covid-19. Região

Metropolitana de São Paulo e Interior do Estado de São Paulo, 2020

\begin{tabular}{|c|c|c|c|c|}
\hline \multirow[b]{2}{*}{ Inserção Laboral } & \multicolumn{2}{|c|}{ RMSP } & \multicolumn{2}{|c|}{ Interior } \\
\hline & $\begin{array}{l}\text { Antes da } \\
\text { pandemia }\end{array}$ & $\begin{array}{l}\text { Depois do } \\
\text { início da } \\
\text { pandemia }\end{array}$ & $\begin{array}{l}\text { Antes da } \\
\text { pandemia }\end{array}$ & $\begin{array}{l}\text { Depois do } \\
\text { início da } \\
\text { pandemia }\end{array}$ \\
\hline Estava trabalhando & 285 & 98 & 94 & 59 \\
\hline Não estava trabalhando & 429 & 599 & 79 & 104 \\
\hline $\begin{array}{l}\text { Começou a trabalhar } \\
\text { depois da pandemia }\end{array}$ & & 12 & & 7 \\
\hline $\begin{array}{l}\text { Não se aplica/não } \\
\text { respondeu }\end{array}$ & 29 & 34 & 30 & 33 \\
\hline Total & 743 & 743 & 203 & 203 \\
\hline
\end{tabular}

Fonte: Pesquisa Impactos da Pandemia de Covid-19 nas Migrações Internacionais no Brasil. Grupo Interdisciplinar de Pesquisa e Extensão em Direitos Sociais e Migração (GIPE) e do Grupo Distribuição Espacial da População (GEDEP)PUCMINAS/Observatório das Migrações em São Paulo-NEPO/UNICAMP, maio a julho de 2020.

Dentre os respondentes à pesquisa na RMSP, a proporção relativa dos que não estavam trabalhando antes da pandemia era de $57,73 \%$, e após o início da pandemia, de $80,61 \%$. Em outras palavras, a pandemia acarretou uma elevação de 39,62\% desta proporção dentre os respondentes na RMSP.

A Tabela 2, por sua vez, nos apresenta informações a respeito das alterações no trabalho e na ocupação por conta das medidas de isolamento social implementadas durante a pandemia. 
Tabela 2 - Imigrantes internacionais participantes da pesquisa segundo as alterações no trabalho/ocupação em função do distanciamento social na pandemia.

Região Metropolitana de São Paulo e Interior do Estado de São Paulo, 2020

\begin{tabular}{l|c|c|c}
\hline \multicolumn{1}{c|}{ Situação } & RMSP & Interior & Total \\
\hline $\begin{array}{l}\text { Não trabalho e já não trabalhava antes da pandemia } \\
\text { (aposentado, desempregado, doméstico/a etc.) }\end{array}$ & 351 & 33 & 384 \\
\hline $\begin{array}{l}\text { Trabalho com o mesmo horário de antes da pandemia, e } \\
\text { tenho deslocado todos os dias para o local de trabalho }\end{array}$ & 38 & 24 & 62 \\
\hline Meu trabalho é em casa (home office) & 38 & 19 & 57 \\
\hline Estou em férias coletivas e forçadas & 18 & 5 & 23 \\
\hline $\begin{array}{l}\text { Fui despedido ou informado pela minha entidade patronal } \\
\text { de que serei despedido nas próximas semanas }\end{array}$ & 51 & 10 & 61 \\
\hline Não vou trabalhar (M p’ap travay, apenas em idioma criolo) & 97 & 17 & 114 \\
\hline Não respondeu & 150 & 95 & 245 \\
\hline Total & 743 & 203 & 946 \\
\hline
\end{tabular}

Fonte: Pesquisa Impactos da Pandemia de Covid-19nas Migrações Internacionais no Brasil. Grupo Interdisciplinar de Pesquisa e Extensão em Direitos Sociais e Migração (GIPE) e do Grupo Distribuição Espacial da População (GEDEP)PUCMINAS/Observatório das Migrações em São Paulo-NEPO/UNICAMP, maio a julho de 2020.

Dos respondentes na RMSP, a maior parte (351 respondentes, 47,24\% do total) declarou não estar trabalhando e também não trabalhava antes da pandemia (perfil que analisamos anteriormente). Um grupo de 97 respondentes $(13,05 \%$ do) afirmou que não vai trabalhar, e 51 respondentes (6,86 do total), afirmou ter sido despedido ou informado de que será despedido nas próximas semanas (tendo em vista o período de realização da pesquisa).

Dentre as estratégias que os imigrantes têm desenvolvido para se (re)inserir profissionalmente no atual contexto de pandemia, na RMSP, das 237 respostas válidas sobre esta questão, a maior parte (100 respondentes, 42,19\%) afirmou estar buscando capacitação laboral. É significativo ainda o grupo dos imigrantes internacionais que afirmaram que necessitam revalidar o diploma universitário (59 respondentes, 24,89\%) bem como daqueles que responderam que nunca tiveram contrato de trabalho (56 respondentes, 23,62\% do total). Chama a atenção, infelizmente, o grupo de 42 respondentes $(17,72 \%$ do total) que afirmou já ter sido enganado por promessas de salários e emprego.

A respeito dos direitos sociais, o conhecimento e acesso a eles, o Gráfico 2 nos apresenta informações acerca da participação, por parte dos imigrantes internacionais respondentes à pesquisa na RMSP, em programas sociais do Governo Federal. Esta participação requer inscrição no Cadúnico, tendo sido 
301 os respondentes inscritos no Cadúnico na RMSP. Destes, 261 (86,71\%) são beneficiários do Programa Bolsa Família, e 30 respondentes (9,96\%) não são beneficiários de nenhum programa social do Governo Federal.

\section{Gráfico 2 - Imigrantes internacionais participantes da pesquisa segundo programas sociais do Governo Federal a que teve acesso. Região Metropolitana de São Paulo, 2020}

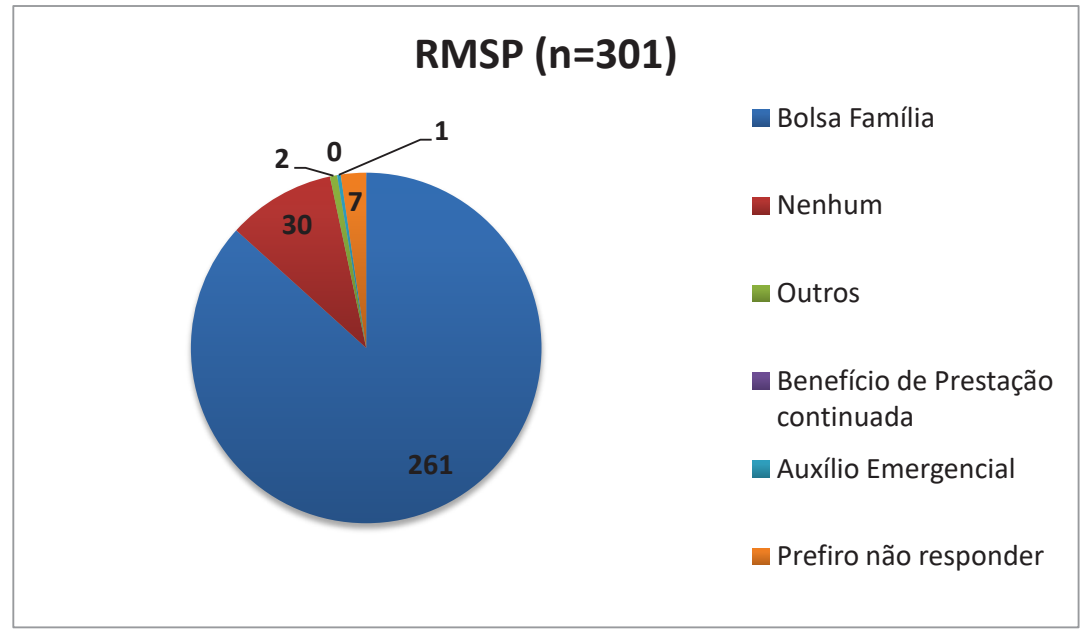

Fonte: Pesquisa Impactos da Pandemia de Covid-19 nas Migrações Internacionais no Brasil. Grupo Interdisciplinar de Pesquisa e Extensão em Direitos Sociais e Migração (GIPE) e do Grupo Distribuição Espacial da População (GEDEP)-PUCMINAS/Observatório das Migrações em São Paulo-NEPO/UNICAMP, maio a julho de 2020 .

O Gráfico 3 apresenta informações dos respondentes que declararam não ter solicitado acesso ao auxílio emergencial ${ }^{5}$, buscando identificação dos motivos desta não solicitação.

\footnotetext{
5 O Auxílio Emergencial "é um benefício financeiro concedido pelo Governo Federal destinado aos trabalhadores informais, microempreendedores individuais (MEI), autônomos e desempregados, e tem por objetivo fornecer proteção emergencial no período de enfrentamento à crise causada pela pandemia do Coronavírus - COVID 19" (CAIXA, 2020). Ele foi aprovado pelo Senado Federal em 30/03/2020, tendo sido sancionado pelo Presidente Jair Bolsonaro em 02/04/2020. As solicitações puderam ser realizadas a partir do dia 07/04/2020 (Castro, 2020), por meios que, desde o princípio, ofereceram muitas dificuldades particularmente aos imigrantes internacionais (ANADEF, 2020). O benefício, no valor de $\mathrm{R} \$ 600,00$, pode ser usufruído por trabalhadores/as autônomos/as, informais, MEls e pessoas desempregadas, ao passo que mães solo têm direito a um benefício de $\mathrm{R} \$ 1.200,00$ por mês.
} 
Gráfico 3 - Imigrantes internacionais participantes da pesquisa que não solicitaram auxílio emergencial segundo motivo. Região Metropolitana de São Paulo, 2020

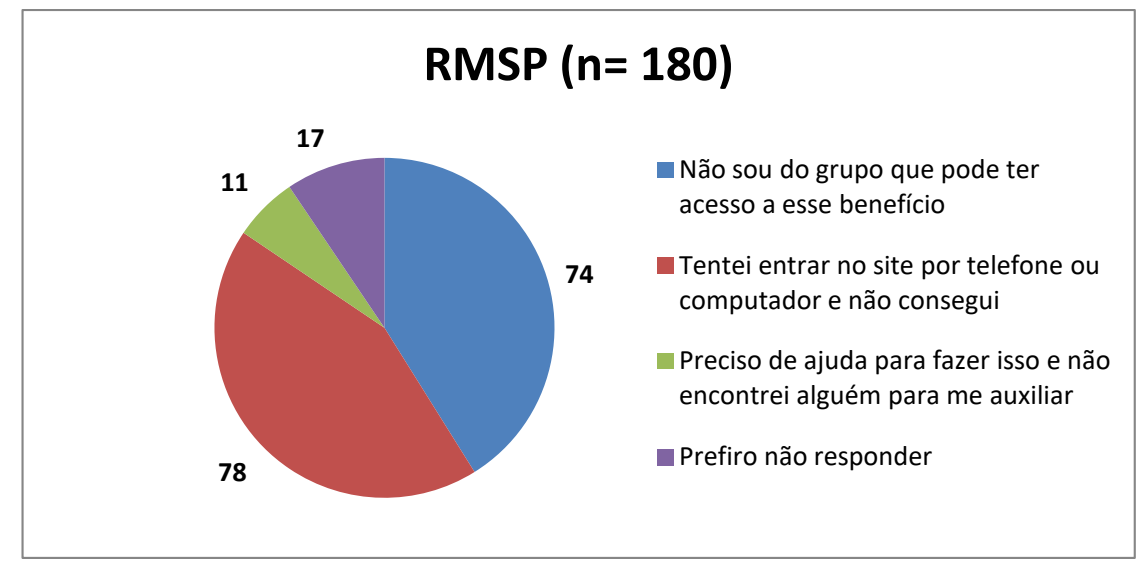

Fonte: Pesquisa Impactos da Pandemia de Covid-19 nas Migrações Internacionais no Brasil. Grupo Interdisciplinar de Pesquisa e Extensão em Direitos Sociais e Migração (GIPE) e do Grupo Distribuição Espacial da População (GEDEP)-PUCMINAS/Observatório das Migrações em São Paulo-NEPO/UNICAMP, maio a julho de 2020.

Dentre os respondentes à pesquisa na RMSP, foram 180 os imigrantes que não solicitaram o auxílio emergencial. Destes, 78 (43,33\%) afirmaram que não solicitaram porque tentaram entrar no site por telefone ou computador e não tiveram êxito; 74 respondentes $(41,11 \%)$ afirmaram que não solicitaram porque não são do grupo que pode ter acesso a esse benefício e 11 respondentes $(6,11 \%)$ afirmaram que não solicitaram porque precisaram de ajuda para fazer a inscrição e não encontraram ninguém para lhes auxiliar.

A respeito do conhecimento sobre os direitos sociais, 635 dos 743 respondentes à pesquisa na RMSP $(85,46 \%)$ afirmaram que têm conhecimentos dos direitos sociais, enquanto 86 (11,57\%) afirmaram que não possuem conhecimento dos direitos sociais. Aqui, observa-se uma especificidade importante dos participantes à pesquisa na RMSP em relação ao Interior Paulista. Nesta região, a maior parte dos respondentes afirmou não ter conhecimento sobre os direitos sociais - respondido por 92 dos 203 imigrantes (45,32\% do total), e 89 afirmaram possuir conhecimento dos direitos sociais $(43,84 \%$ do total). A concentração, nos contextos urbanos metropolitanos, de associações migrantes e entidades da sociedade civil que atuam no acolhimento e acompanhamento a imigrantes, além de órgãos governamentais e de grupos de pesquisa da Universidade, tornam as informações sobre os direitos sociais mais presentes na RMSP do que no Interior paulista.

A respeito das decisões de consumo e de mobilidade tomadas durante a pandemia (questão respondida por 683 imigrantes), 383 respondentes (56,07\%) afirmaram estar reduzindo suas despesas, ao passo que 337 respondentes $(49,34 \%)$, disseram estar em situação muito delicada com dificuldades inclusive de 
sobrevivência; 65 respondentes $(9,51 \%)$ declararam já ter solicitado empréstimos a amigos e/ou instituições bancárias e um grupo, pequeno mas muito significativo do ponto de vista da teoria migratória, de 20 respondentes (2.92\%) afirmou estar buscando informações sobre outros países para emigrar, indicando, com isso, um impacto da pandemia de Covid-19 e das dificuldades encontradas no Brasil sobre a mobilidade internacional.

Quanto às preocupações dos imigrantes internacionais a respeito de seu futuro, importante indicador das condições de vida, sociabilidade e dos projetos migratórios, é importante salientar que essa informação, emitida pelos próprios imigrantes, constitui elemento importante para reflexões e contribuições aos estudos migratórios, especialmente às mediações entre mobilidade humana e saúde. Dentre os respondentes à pesquisa na RMSP, a principal preocupação ou medo verbalizado pelos imigrantes internacionais refere-se à sua saúde e segurança alimentar (650 respostas), expressando claramente os efeitos da pandemia sobre as suas condições de vida. A seguir, vieram as preocupações relacionadas ao trabalho (497 respostas), o medo quanto ao aumento da discriminação (495 respostas), o temor de dissolução dos laços sociais (436 respostas) e medos relacionados à aspectos legais e de documentação (158 respostas).

\section{Considerações Finais}

Neste artigo, buscamos refletir sobre os impactos da pandemia de Covid-19 sobre os imigrantes internacionais na Região Metropolitana de São Paulo, a partir de dados da pesquisa "Impactos da Pandemia de Covid nas Migrações Internacionais" (PUC-MG, UNICAMP, 2020). A importância, tanto qualitativa como quantitativa, dos resultados da pesquisa adquire magnitude ainda maior em razão da escassez de dados oficiais sobre casos e óbitos por Covid-19 entre imigrantes internacionais no Brasil. Essa escassez, como vimos, é expressão de uma xenofobia estrutural, que condiciona a invisibilidade de estrangeiros nos registros hospitalares e que se soma ao próprio racismo estrutural, tendo em vista o quesito raça/cor não ser de preenchimento obrigatório nestes mesmos registros. A ausência de tais informações, se de um lado obstaculiza a identificação das especificidades de raça/cor e nacionalidade, dificultando com isso a elaboração de políticas públicas específicas para negros/as, pardos/as, pretos/as e imigrantes, de outro lado gera mobilizações, tanto institucionais como da própria sociedade civil, importantes e extremamente necessárias para interações sociais e laborais assentadas no acolhimento, no trabalho digno e na universalidade dos direitos no Brasil - na proteção, enfim, de imigrantes internacionais sob a ótica dos Direitos Humanos (Ramos, Vedovato, Baeninger, 2020).

Dentre as iniciativas institucionais, é importante destacar o PL 2726/2020, de autoria do Deputado Federal Alexandre Padilha (PT-SP), Ministro da Saúde entre 2011 e 2014. Este Projeto de Lei 


\begin{abstract}
Determina aos órgãos integrantes do Sistema Único de Saúde e instituições privadas de assistência à saúde a inclusão nos registros de pessoas suspeitas de contaminação, contaminadas, hospitalizadas e falecidas por Covid-19 de marcador étnico-racial conforme as categorias do Instituto Brasileiro de Geografia e Estatística, de localização e de gênero, para a produção de dados oficiais de contaminação e mortalidade pela Covid-19 e que tais dados passem a fazer parte da apresentação pública dos dados de infecção e mortalidade. (BRASIL, 2020a)
\end{abstract}

A este Projeto de Lei, associações migrantes e grupos de defesa de imigrantes da sociedade civil propuseram emenda, já adicionada, para que o quesito de nacionalidade fosse também incorporado aos registros, sendo seu preenchimento obrigatório. Atualmente, este PL encontra-se no Plenário da Câmara dos Deputados, em regime de urgência desde Maio de 2020, todavia ainda sem previsão de votação.

De acordo com o sanitarista James Berson Lalane, natural do Haiti e mestrando no Programa de Pós-Graduação em Medicina Preventiva da USP, "a falta de dados sobre os migrantes cria obstáculos dentro do sistema de saúde, traz resultados negativos nas formulações de políticas públicas de saúde aos migrantes, e dificulta a inserção do migrante dentro da sociedade. (Silva, Magalhães, 2020, p. 56)

Outra mobilização institucional importante é o PL 2699/2020, de autoria da Deputada Fernanda Melchionna (PSOL-RS), que busca instituir "medidas emergenciais de regularização migratória no contexto da pandemia de COVID19" (BRASIL, 2020b). Este PL, beneficiado pela atuação de associações migrantes e entidades de acolhimento a imigrantes, parte do entendimento de que:

A pandemia de COVID-19 e seus impactos socioeconômicos severos e duradouros tendem a aprofundar ainda mais a exclusão e a vulnerabilidade que imigrantes e refugiados, sobretudo aqueles com status migratório irregular, enfrentam no Brasil. Além de prejudicar as condições de vida dessas pessoas, a irregularidade migratória ameaça a efetividade das políticas públicas no combate à pandemia e à crise econômica no país, sendo urgente que este Parlamento tome iniciativas para sanála. É notório que esta pandemia tem afetado de maneira diferenciada populações mais vulneráveis em todo o mundo, e é sabido que migrantes e refugiados sempre estiveram entre as pessoas que enfrentam maiores desafios no acesso a serviços e políticas públicas. Ainda, de acordo com a Organização Internacional do Trabalho (OIT), quando conseguem encontrar emprego, imigrantes também enfrentam, majoritariamente, condições de informalidade e precariedade trabalhistas alarmantes. (BRASIL, 2020b)

Por tal razão, também as iniciativas da própria sociedade civil, especialmente aquelas protagonizadas pelos imigrantes, têm sido de fundamental importância para que as estratégias de enfrentamento à Covid-19 no Brasil levem em conta as especificidades da população migrante. Manifestação importante da organização dos imigrantes e de sua capacidade de incidência política é a campanha "Regularização Já". A campanha possui clara inspiração na anistia promovida em Portugal em março de 2020, quando foram regularizados todos os pedidos de residência que estavam pendentes, e remete, também, a um dos vetos impostos pelo então Presidente Michel Temer à Nova Lei de Migrações - o veto ao artigo 
que estabelecia a anistia para imigrantes indocumentados no Brasil. Ao ser promovida pelos próprios imigrantes, apresenta elementos importantes de suas sociabilidades, como a denúncia ao fato de que, por conta de indocumentação, não é raro imigrantes não buscarem atendimento médico.

Este artigo abre, também, uma agenda de pesquisa, expressa nos pontos sobre os quais não pudemos nos aprofundar nestas páginas, como as especificidades de gênero no impacto que a doença tem ocasionado, as particularidades regionais em termos de outras espacialidades que não a RMSP, como, por exemplo, a Macrometrópole Paulista (Bógus, Pasternak, Magalhães, 2020; Baeninger, Demétrio, Domeniconi, 2020), e, ainda, o conjunto de entrevistas em profundidade que foram realizadas com imigrantes também no âmbito da citada pesquisa. O cenário atual exige uma reflexão teórica sobre este e outros pontos capaz de desvelar as novas e complexas dimensões da relação entre a mobilidade humana e as emergências epidemiológicas.

\section{Referências bibliográficas}

ANADEF, Associação Nacional dos Defensores Públicos Federais. DPU ajuíza ACP para garantir pagamento do auxílio emergencial a migrantes. 2020. Disponível em: < https ://www.anadef.org.br/noticias/ultimas-noticias/item/dpu-ajuiza-acp-para-garantirpagamento-do-auxilio-emergencial-a-migrantes.html\#: :text=A\%20DPU\%20 afirma\%20na\%20a\%C3\%A7\%C3\%A3o,de\%20resid\%C3\%AAncia)\%2C\%20 bem\%20como\%20o>.

BAENINGER, Rosana; DEMÉTRIO, Natália; DOMENICONI, Joice (coords.). Atlas Temático da Macrometrópole Paulista, Regiões Metropolitanas e Regiões Administrativas. Campinas - SP: Núcleo de Estudos 'Elza Berquó' NEPO - Unicamp, 2020.

BAENINGER, Rosana; VEDOVATO, Luís Renato; NANDY, Shailen (orgs.). Migrações Internacionais e a Pandemia de Covid-19. Campinas - SP: Editora do NEPO - Núcleo de Estudos de População "Elza Berquó", 2020.

BAENINGER, Rosana et al. Migrações Sul-Sul. Campinas: Nepo/Unicamp/UNFPA, 2018.

BAENINGER, Rosana et al. (org.). Imigração Haitiana no Brasil. Jundiaí: Paco Editoral, 2016.

BAPTISTA, Dulce Maria Tourinho; MAGALHÃES, Luís Felipe Aires (org.). Migrações em expansão no mundo em crise. São Paulo - SP: EDUC, 2020.

BASSO, Pietro. Racismo de Estado e antirracismo de classe na Europa. São Paulo: Margem Esquerda, 2015.

BÓGUS, Lucia Maria Machado; MAGALHÃES, Luís Felipe Aires. Desigualdades socioespaciais e pandemia: impactos metropolitanos da Covid-19. In: PASSOS, João Décio (org.). A Pandemia do Coronavírus: Onde estivemos? Para onde vamos? São Paulo: Paulinas, 2020.

BÓGUS, Lucia; PASTERNAK, Suzana; MAGALHÃES, Luís Felipe Aires. Metropolização, governança e direito à cidade: dinâmicas, escalas e estratégias. São Paulo: EDUC, PIPEq, 2020. 
BRASIL, Câmara dos Deputados. PL 2726/2020. Brasília, DF. Em tramitação. 2020a. Disponível em: <https://www.camara.leg.br/propostas-legislativas/2252866>.

BRASIL, Câmara dos Deputados. PL 2699/2020. Brasília, DF. Em tramitação. 2020b. Disponível em: <https://www.camara.leg.br/proposicoesWeb/prop_mostrarintegra ;jsessionid=2D71A0DE5805711A6E6F3843C94164C8. proposicoesWebExterno1? codteor $=1894355 \&$ filename $=$ Tramitacao $-\mathrm{PL}+2699 / 2020>$.

CAIXA ECONÔMICA FEDERAL. Auxílio Emergência. 2020. Disponível em: < https:// www.caixa.gov.br/auxilio/PAGINAS/DEFAULT2.ASPX $>$.

CASTRO, Bárbara (org.). Covid-19 e Sociedade: Ensaios sobre a experiência social da pandemia. Campinas - SP: Unicamp, IFCH, 2020.

FERNANDES, Duval Magalhães; BAENINGER, Rosana. Pesquisa Impactos da Pandemia de Covid-19 nas Migrações Internacionais no Brasil. Grupo Interdisciplinar de Pesquisa e Extensão em Direitos Sociais e Migração (GIPE) e do Grupo Distribuição Espacial da População (GEDEP)-PUCMINAS/Observatório das Migrações em São Paulo-NEPO/UNICAMP, maio a julho de 2020. Disponível em: <https://www. nepo.unicamp.br/publicacoes/livros/impactos_pandemia/COVID\%20NAS\%20 MIGRA\%C3\%87\%C3\%95ES\%20INTERNACIONAIS.pdf>.

MACHADO, Leandro. Coronavírus: a rodovia federal que 'levou' a covid-19 para o interior de Pernambuco. BBC News, 2020. Disponível em: < https:/www.bbc.com/ portuguese/brasil-52332235>.

MAGALHÃES, Luís Felipe Aires; BÓGUS, Lúcia; BAENINGER, Rosana. Migrantes Haitianos e Bolivianos na Cidade de São Paulo: Transformações econômicas e territorialidades migrantes. REMHU, Revista Interdisciplinar da Mobilidade Humana, Brasília, v. 26, n. 52, p. 75-94, abr. 2018.

MARTINS, José de Souza. Fronteira: a degradação do outro nos confins do humano. São Paulo: Hucitec, 1997.

PERES, Roberta. Imigração e Gênero: As mulheres haitianas no Brasil. In: BAENINGER, Rosana et al. (org.). Imigração Haitiana no Brasil. Jundiaí: Paco Editoral, 2016.

RAMOS, André de Carvalho; VEDOVATO, Luís Renato; BAENINGER, Rosana. Nova Lei de Migração: Os três primeiros anos. Campinas - SP: Núcleo de Estudos de População 'Elza Berquó' - UNICAMP, 2020.

ROSETA, Helena. A Pandemia e as Desigualdades. Público, 2020. Disponível em: $<$ https://www.publico.pt/2020/05/14/opiniao/opiniao/pandemia-desigualda des$1916253>$.

SASSEN, Saskia. As cidades na Economia Mundial. São Paulo: Studio Nobel, 1998.

SAYAD, Abdelmalek. A Imigração ou os Paradoxos da Alteridade. São Paulo: Edusp, 1998.

SILVA, Carla Craice da; MAGALHÃES, Luís Felipe Aires. Imigrantes, direitos e a pandemia da Covid-19. In: SANTOS, Márcio André dos; PARADIS, Clarisse. As Humanidades e os Efeitos da Covid-19: Reflexões a partir da Unilab. Horizontes ao Sul, n. 1, 2020. Disponível em: < https://docs.wixstatic.com/ugd/c64666_6498970 65ab54d58af3013e6078f1f12.pdf $>$. 
SILVA, Camila Rodrigues da; MAGALHÃES, Luís Felipe Aires; MORTARI, Paulo; BAENINGER, Rosana. Emergências Epidemiológicas e Mobilidade Humana. São Paulo: Centro Paula Souza, 2020.

TRUZZI, Oswaldo. Redes em Processos Migratórios. Revista Tempo Social, v. 12, p. 199-218, 2008.

VILLEN, Patrícia. O estigma da ameaça ao emprego pelos "periféricos na periferia": crise e imigração no Brasil. Rua, Unicamp, v. II, p. 247-264, 2015.

ZIEGLER, Maria Fernanda. Padrão de disseminação urbana da COVID-19 reproduz desigualdades territoriais. Agência FAPESP, 2020. Disponível em: < http://agencia. fapesp.br/padrao-de-disseminacao-urbana-da-covid-19-reproduz-desigualdadesterritoriais/33226/\#.XsfOC2EcV3M.whatsapp>. 